eCommons@AKU

March 2017

\title{
Distribution of gastric carcinoma in an area with a high prevalence of Helicobacter pylori.
}

javed Yakoob

Aga Khan University, javed.yakoob@aku.edu

syeda sadia fatima

Aga Khan University

Z Abbas

Aga Khan University, zaigham.abbas@aku.edu

syed farrukh mustafa

Aga Khan University

Hamza Abdur Rahim Khan

Aga Khan University

See next page for additional authors

Follow this and additional works at: http://ecommons.aku.edu/

pakistan_fhs_mc_med_gastroenterol

Part of the Gastroenterology Commons

\section{Recommended Citation}

Yakoob, j., fatima, s. s., Abbas, Z., mustafa, s. f., Khan, H. A., raghib, m. f., Awan, S., Ahmad, Z. (2017). Distribution of gastric carcinoma in an area with a high prevalence of Helicobacter pylori.. The Turkish journal of gastroenterology : the official journal of Turkish Society of Gastroenterology., 28(2), 98-103.

Available at: http://ecommons.aku.edu/pakistan_fhs_mc_med_gastroenterol/113 


\section{Authors}

javed Yakoob, syeda sadia fatima, Z Abbas, syed farrukh mustafa, Hamza Abdur Rahim Khan, muhammad faraz raghib, Safia Awan, and Zubair Ahmad 


\section{Distribution of gastric carcinoma in an area with a high prevalence of Helicobacter pylori}

Javed Yakoob', Syeda Sadia Fatima², Zaigham Abbas', Syed Farrukh Mustafa', Hamza Abdur Rahim Khan', Muhammad Faraz Raghib², Safia Awan', Zubair Ahmad³

'Department of Medicine, Aga Khan University, Karachi, Pakistan

²Department of Biological Biomedical Sciences, Aga Khan University, Karachi, Pakistan

${ }^{3}$ Department of Pathology and Laboratory Medicine, Aga Khan University, Karachi, Pakistan

\section{ABSTRACT}

Background/Aims: South Asia is an enigma for gastric cancer (GC) because it is a low risk region with a high prevalence of Helicobacter pylori (H. pylori) infections. We evaluated the trend of GC clinical presentation and risk factors in patients with dyspeptic symptoms.

Materials and Methods: The medical records of patients, coded by the international classification of diseases (ICD-10-CM, 2015, Diagnosis Code C16.9) for malignancies of stomach diagnosed by esophagogastroduodenoscopy (EGD) and histopathology, were studied.

Results: 394 GC cases with a mean age of $54 \pm 15$ years, range of 18 to 88, were analyzed. 256 (65\%) were male. Distal non-cardiac and cardiac tumors were 302 (77\%) and 92 (23\%) cases, respectively. The WHO classification of GC defined 222 (56\%) cases as intestinal type adenocarcinoma, 68 (17\%) cases as signet ring cell carcinoma (SRC), 62 (16\%) cases as diffuse type and 42 (11\%) cases as B cell non-Hodgkin lymphoma. The co-morbid conditions associated with GC were H. pylori infection (positive in 246 (62\%) cases), diabetes mellitus type 2 (in 90 (23\%) cases), and cigarette smoking (in 94 (24\%) cases). Of the male patients, 88 (34\%) ( $p<0.001)$ were smokers. Body mass index was abnormal in all age groups and in both sexes. Cardiac regions for $\mathrm{GC}$ were more common in the 46- to 60-year old age range and in males. Diffuse GC was seen in all age groups but there were significantly more common in the 18- to 45-year old age range. Gastric non-Hodgkin's lymphoma was seen at an early age of $18-45$ years in $14(12 \%)$ and a later of $61-88$ years in 20 (15\%).

Conclusion: Intestinal type GC is common at all ages but SRC and diffuse GC are more common in patients less than 50 years old. SRC and diffuse GC were not specific to the elderly in our study population.

Keywords: Gastric carcinoma, male, age, H. pylori, noncardiac, intestinal type carcinoma, signet cell carcinoma

\section{INTRODUCTION}

Gastric carcinoma (GC) is one of the major causes of mortality and morbidity worldwide (1) and it is also one of the leading causes of death worldwide (2). GC prognosis remains poor as it is rarely detected early, and the majority of cases show distant metastasis at the time of diagnosis $(3,4)$. Developing countries account for twothirds of the reported incidences of GC worldwide (5). The incidence of GC in both men and women is concentrated primarily in Asia, and the highest incidence has been reported in Asian countries e.g. Japan, China and Korea $(6,7)$.
Helicobacter pylori (H. pylori) is a major cause of gastroduodenal ulcer and risk factor for GC and lymphoma. In developing countries located in Asia e.g., Pakistan and India, H. pylori infection is frequent in the general population and occurs at an early age. In our country, $H$. pylori is acquired at an early age and H.pylori seropositivity in children (11-15 years old) is $53.5 \%$ (8). In contrast, in developed Asian countries like Japan and Singapore, the frequency of $H$. pylori infection is reported to be somewhat lower $(9,10)$. In the United States, the prevalence of $\mathrm{H}$. pylori has decreased to approximately $10 \%$ in the white middle and upper class populations

Address for Correspondence: Javed Yakoob E-mail: javed.yakoob@aku.edu

Received: October 28, 2016 Accepted: December 19, 2016 Available Online Date: January 25, 2017

(c) Copyright 2017 by The Turkish Society of Gastroenterology • Available online at www.turkjgastroenterol.org • DOI: 10.5152/tjg.2017.17607 
younger than 50 years old (11). H. pylori is transmitted by the feco-oral route. It is associated with areas of overcrowding, poor sanitation, lower socioeconomic status, and poor water supply because these are risk factors for $\mathrm{H}$. pylori infection. As a result, there is a higher frequency and lower age of acquisition for $\mathrm{H}$. pylori in less developed Asian countries $(12,13)$. In Pakistan, there is a high prevalence of $H$. pylori, but the prevalence of $\mathrm{GC}$ is low. This study determined the distribution of GC in our patients with upper gastrointestinal symptoms and risk factors associated with GC.

\section{MATERIALS AND METHODS}

In this cross-sectional study, the medical records of patients aged 18 years and over who attended the hospital were reviewed. These patients presented with pain, nausea or vomiting, weight loss, hematemesis, melena, and had an esophagogastroduodenoscopy (EGD) between January 2000 and January 2016. The "gastric carcinoma cases" were defined as patients who fulfill the 2015 ICD-10-CM Diagnosis Code C16.9 for malignancies of the stomach. Three hundred and ninety-four patients fulfilled these criteria. The demographic characteristics that were taken into account included: mean age, sex, address of permanent residence, body weight $(\mathrm{kg})$, height $(\mathrm{cm})$, symptoms, use of medications [analgesics, proton pump inhibitors (PPIs), etc.], diagnosis, blood glucose levels, lipid profile, hemoglobin levels, hemoglobinA1c levels, liver function test, complete blood count, H. pylori serology, (14) carbon labeled-urea breath test $\left({ }^{14} \mathrm{C}-\mathrm{UBT}\right)$ or stool antigen test $(\mathrm{HpSA})$, and tumor markers [protein CA 125 (cancer antigen 125) and carcinoma embryonic antigen (CEA)] were recorded. Cigarette smoking, alcohol intake, and occupational history were also noted.

\section{Study Design}

This was a cross sectional study.

\section{Setting}

Retrospective data collection from patient medical records was performed after obtaining approval by the institutional ethics review committee.

\section{Inclusion Criteria}

All patients, irrespective of sex, age, and ethnic background, that presented with upper gastrointestinal symptoms and diagnosed as having GC between January 2000 and January 2016 were included.

\section{Exclusion Criteria}

Individuals with a history of gastrectomy for GC, aplastic anemia, scleroderma, gastric lymphoma, and gastrointestinal stromal tumor (GIST) were excluded.

\section{Endoscopy}

The morphology of GC was described as exophytic, ulcerated, infiltrative, or combined. Bormann's classification described the appearance of GC as type I for polypoid growth, type I| for fun- gating growth, type III for ulcerating growth, and type IV for diffusely infiltrating growth (linitis plastica in SRC).

Esophageal carcinoma anatomic classification was if its epicenter was in the lower thoracic esophagus or gastroesophageal junction (GEJ) or within the proximal $5 \mathrm{~cm}$ of stomach (i.e., cardia) with the tumor mass extending into GEJ or distal esophagus. If the origin was $>5 \mathrm{~cm}$ distal to the GEJ, or within $5 \mathrm{~cm}$ of GEJ but did not extend into GEJ or esophagus, it was grouped as GC (14).

\section{Histopathology}

At the time of endoscopy, at least 2 or more biopsies were obtained from gastric abnormalities with standard biopsy forceps and tissues were submitted for histopathological examination. Specimens were fixed overnight in 10\% buffered formalin and gross examination performed the next day was followed by paraffin embedding. Slides were stained with hematoxylin and eosin. The reporting (according to the TNM staging system) incorporated gross examination, tumor location, type and grade, depth of invasion, surgical resection margins, and lymph node status. Histological classification of GC was based on Lauren's criteria (15).

\section{Statistical Analysis}

Results were expressed as mean \pm standard deviation. Univariate analysis was performed using an independent sample t-test, Pearson Chi-square test or Fisher Exact test where applicable. A p value $<0.05$ was considered significant. Statistical interpretation of data was performed using IBM Statistical Package for the Social Sciences Statistics (IMB SPSS Statistics; Armonk, NY, USA) version 19.0.

\section{Technique}

The technique used was non-probability consecutive sampling.

\section{Data Collection Procedure}

Exemption from the institutional ethics review committee (ERC) was obtained. All pathologically documented gastric cancer records during a 16-year period (from 2000 to 2016) were recorded. Cases of GC presenting for the first time during the 16- year period were identified. All demographic, clinical, and endoscopic data from each patient were gathered and analyzed.

\section{RESULTS}

There were 394 cases. The mean age was $53 \pm 15$ (range: 18-88) years of age. Male patients constituted $256(65 \%)$ cases and 138 (35\%) cases were female patients.

\section{Risk Factors}

There was no difference in the distribution of $H$. pylori infection in patients in relation to age, sex, and site of malignancy (Table 1,2). The co-morbid conditions associated with GC were diabetes mellitus type 2 in 90 (23\%) case, essential hypertension in 
Table 1. Clinical details of the patients with gastric carcinoma $(n=394)$

\begin{tabular}{|c|c|}
\hline Age (year) mean $\pm S D$ & $54 \pm 15$ \\
\hline Range & $18-88$ \\
\hline \multicolumn{2}{|l|}{ Sex } \\
\hline Male/Female & $256 / 138$ \\
\hline Symptoms & n (\%) \\
\hline Weight loss & $290(74)$ \\
\hline Nausea & $232(59)$ \\
\hline Loss of appetite & $216(55)$ \\
\hline Epigastric pain & $184(53)$ \\
\hline Dysphagia & $114(29)$ \\
\hline Melena & $66(17)$ \\
\hline Constipation & $68(17)$ \\
\hline Gastric outlet obstruction & $54(14)$ \\
\hline Hematemesis & $48(12)$ \\
\hline \multicolumn{2}{|l|}{ Endoscopy features } \\
\hline Diffuse & $224(59)$ \\
\hline Fungoid & 76 (19) \\
\hline Ulceration & $66(17)$ \\
\hline Polypoid & $18(5)$ \\
\hline \multicolumn{2}{|l|}{ Site of tumor } \\
\hline Cardiac & $92(23)$ \\
\hline Non-cardiac & $302(77)$ \\
\hline \multicolumn{2}{|l|}{ Histology } \\
\hline Intestinal type & $222(56)$ \\
\hline Signet cell carcinoma & $68(17)$ \\
\hline Diffuse & $62(16)$ \\
\hline Lymphoma & $42(11)$ \\
\hline \multicolumn{2}{|l|}{ Histology } \\
\hline Well differentiated & $74(19)$ \\
\hline Moderately differentiated & $194(49)$ \\
\hline Poorly differentiated & $126(32)$ \\
\hline \multicolumn{2}{|l|}{ Risk factors } \\
\hline Helicobacter pylori & $246(62)$ \\
\hline Cigarette smoker & $94(24)$ \\
\hline Alcohol & $12(3)$ \\
\hline \multicolumn{2}{|l|}{ Metastases } \\
\hline Lymph nodes & $228(60)$ \\
\hline Peritoneum & $64(16)$ \\
\hline Liver & $48(13)$ \\
\hline Pulmonary & $38(11)$ \\
\hline Bone & $8(2)$ \\
\hline Small intestine & $4(1)$ \\
\hline Pancreas & $4(1)$ \\
\hline
\end{tabular}

68 (23\%) cases, and cigarette smoking in 94 (24\%) cases. The distribution of GC was not related to the history of smoking. However, male patients [88 $(34 \%)$ cases $(p<0.001)$ ] were more commonly smokers than female patients [6 (4\%) cases] (Table 2). Body mass index was noted to be abnormal in all the age groups and in both sexes (Table 2).

\section{Gastric Tumors}

Gastric carcinoma arising from the non-cardiac region of the stomach was equally common in all age groups (Table 2). However, cardiac region tumors were more common in 46- to 60-year old patients and in males (Table 2). GC arising in the antrum were common in the 18 to 45 -year old age group [68 $(60 \%)$ cases $(p=0.196)]$, but they were equally common in the two other age groups (Table 2). GC arising from the gastric lesser curve were more common in male patients compared to female patients and in the 46- to 60-year old age group [38 $(25 \%)$ cases $(p=0.006)]$ compared to the other age groups (Table 2). Diffuse GC was seen in all three age groups, but they were significantly more common in the younger age group (18- to 45-year old) and did not show any sex-related distribution (Table 2). Intestinal type GC was found equally in all age groups and also did not show any sex-related distribution (Table 2). GC, fungoid in shape in 36 (28\%) cases, was significantly more common in the 61- to 88-year old age group than in the younger age groups (Table 2). SRCs were found frequently in the 18 to 45 -year old and 46- to 60-year old age groups (Table 2). Gastric non-Hodgkin's lymphoma was not associated with sex and demonstrated two peaks in our patients: 14 (12\%) cases in the 18- to 45-year old group and 20 (15\%) cases in the 61- to 88-year old group (Table 2).

\section{Gastric Metastases}

Lymph node metastases were equally common in all age groups and marginally more common in female patients than male $98(71 \%)$ vs. $156(61 \%)(p=0.046)$, respectively (Table 2 ). Liver metastases were common in the older age group and occurred equally in both sexes (Table 2). Pulmonary metastases were also significantly more common in the older age group and in female patients [32 (23\%) cases $(p<0.001)$ ] compared to male patients (26 (10\%) cases) (Table 2). Peritoneal metastases were common in the 18- to 45-year old age group compared to the older age groups, and also significantly more common in females [32 $(23 \%)$ cases $(p<0.001)]$ compared to males [26 (10\%) cases] (Table 2).

\section{DISCUSSION}

Gastric carcinomas were twice more common in males than in females. Only $32 \%$ of the GC cases were seen in elderly patients (61- to 88-year old age group). The study did not show a significant distribution in the elderly population as our patients with GC had a median age of 55 years. This is different from GC prevalence in other populations where GC is usually observed in patients 70 and older (16). Among the risk factors for $G C$, the H. pylori infection factor did not vary in the different age groups nor demonstrated a sex distribution (Table 2). H. pylori infection diagnoses involved in these cases was biopsy obtained at endoscopy for histology and did not include usage of a ${ }^{14} \mathrm{C}-$ UBT or HpSA test, which are better diagnostic tests (17). In practice, the H. pylori treatment prescribed is not based on local H. pylori antibiotic sensitivities. Post-treatment of H. pylori infection, there was an absence of documentation regarding eradication of the infection.

Smoking was common in all age groups, particularly in male patients (Table 2). This is in keeping with our National Health Survey, which described $46 \%$ men and $5.7 \%$ women as smoking tobacco (contributing to 80,000 deaths annually) (18). A cross sectional survey in a tertiary care center revealed that $39 \%$ of patients aged 18 years or older had either hypertension 
Table 2. Association of gastric carcinoma with age and sex

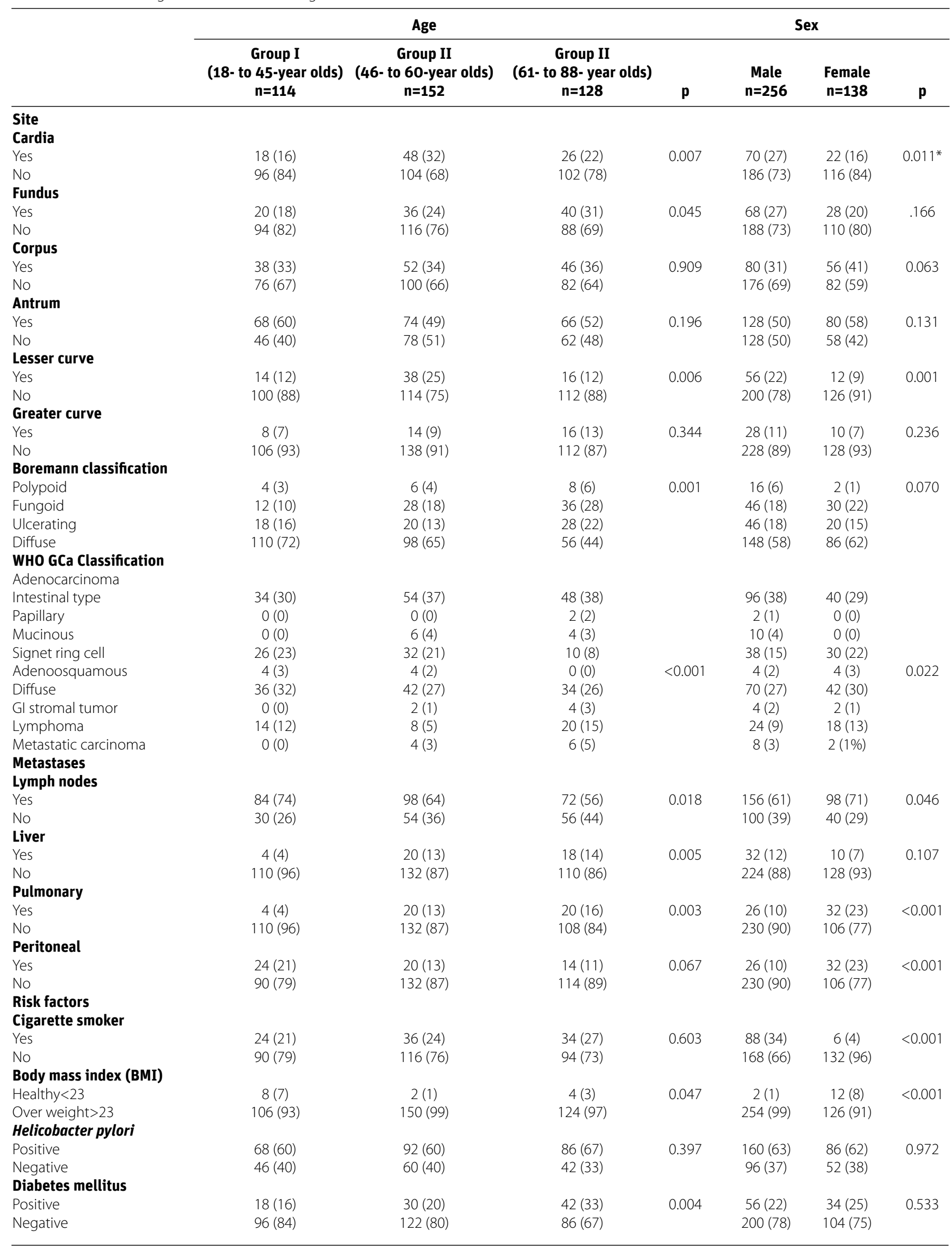


or dyslipidemias with a history of active smoking (19). Based on the data of the National Health Survey, the overall prevalence of smoking among 15-year olds or older was $15.2 \%$ and the prevalence of smoking was $28.6 \%$ in men compared to $3.4 \%$ in women (20). The incidence of GC in male patients was in keeping with the prevalence of smoking in the male population. Increased salt intake has been described as an independent risk factor of GC. In a population based study, an increased dietary salt intake was documented among different communities in Karachi (21). Furthermore, according to the National Health Survey, $25.0 \%$ of the population was overweight or obese (22). The majority of patients with GC had a BMl that was deemed "overweight" in the majority of our GC patients, regardless of age or sex (Table 2). This is in agreement with the high BMI that was associated with the distribution of GC. Diabetes mellitus type 2 was significantly associated with GC in all age groups with a marked distribution in the 61- to 88-year old group [33\% $(p=0.004)$ ] (Table 2). This is in keeping with the high prevalence of diabetes mellitus in this age group (equal sex distribution). According to the 2011 figure of the World Health Organization, the prevalence of diabetes mellitus in our population was the $7^{\text {th }}$ highest in the world at $12.9 \%$, which is the $10 \%$ of our population (23).

The gastric rich lymphatic and vascular supply explained extensive lymph node and liver metastases in GC at presentation. Lymph nodes metastases were equally common in all age groups regardless of sex. However, they were more common in the early age group of 18- to 45-year olds (84 (74\%) cases) compared the older age group of 61- to 88-year olds (72 $(56 \%)$ cases) (Table 2). At presentation, liver metastases were common in the two older age groups (Table 2). Pulmonary metastases [32 $(23 \%)$ cases $(p<0.001)]$ were more common in female compared to male (26 (10\%) cases) patients. In previous studies, diffuse GC was found commonly in young female patients $(24,25)$ while intestinal GC (associated with intestinal metaplasia) and $H$. pylori infection was found equally in all age groups $(25,26)$. In an earlier local study, $53 \%$ of GC cases were located in the gastric antrum and 35\% in the proximal part (27). However in the present study, distal gastric tumors and cardiac tumors were $77 \%$ and $23 \%$, respectively (Table 1 ).

The implications of this study is that the education of the population at large and effective treatment of the risk factors of GC should be offered to the patients. In the absence of effective screening for early diagnosis of GC, we will continue to see patients with extensive disease progression at presentation.

Gastric carcinoma incidence has decreased in industrialized countries. GC is still a cause of mortality and morbidity in developing countries. A non-cardiac predominant disease was shown here to be associated with H. pylori infection and will require more effective management and eradication. In conclusion, GC is not an elderly disease in our population, which is different from developed countries.
Ethics Committee Approval: Ethics committee approval was received for this study from the ethics committee of Aga Khan University Hospital (3549-Med-ERC-15).

\section{Informed Consent: N/A.}

Peer-review: Externally peer-reviewed.

Author Contributions: Concept - J.Y., S.S.F., Z.Abbas., Z.A.; Design - Y.J., S.S.F., Z.Abbas.; Supervision - J.Y., S.S.F.; Resources - Z.A.; Materials - S.F.M., H.A.R.K., M.F.R.; Data Collection and/or Processing - S.F.M., H.A.R.K., M.F.R.; Analysis and/or Interpretation - J.Y., Z.Abbas., Z.A., S.A.; Literature Search - J.Y., Z.Abbas.; Writing Manuscript - J.Y., Z.Abbas.; Critical Review - S.S.F., Z.Abbas., Z.A.

Conflict of Interest: No conflict of interest was declared by the authors.

Financial Disclosure: The authors declared that this study has received no financial support.

\section{REFERENCES}

1. Ferlay J, Soerjomataram I, Dikshit R, et al. Cancer incidence and mortality worldwide: Sources, methods and major patterns in GLOBOCAN 2012. Int J Cancer 2015; 136: E359-86. [CrossRef]

2. Murray CJ, Vos T, Lozano R, et al. Disability-adjusted life years (DALYs) for 291 diseases and injuries in 21 regions, 1990-2010: a systematic analysis for the Global Burden of Disease Study 2010. Lancet 2012; 380: 2197-23. [CrossRef]

3. Ozkan K, Turkkan E, Ender K, et al. 5-Fluorouracil, epirubicin and cisplatin in the treatment of metastatic gastric carcinoma: a retrospective analysis of 68 patients. Indian J Cancer 2005; 42: 85-8. [CrossRef]

4. Stewart BW, Kleihues P. World cancer report. Lyon: IARC Press; 2003.

5. Jemal A, Ward E, Thun M. Declining death rates reflect progress against cancer. PLoS One 2010; 5: e9584. [CrossRef]

6. Pourfarzi F, Whelan A, Kaldor J, Malekzadeh R. The role of diet and other environmental factors in the causation of gastric cancer in Iran-A population based study. Int J Cancer 2009; 125: 1953-60. [CrossRef]

7. Ferlay J, Bray F, Pisani P, Parkin DM. GLOBOCAN 2002: cancer incidence, mortality and prevalence worldwide, version 2.0. LyonFrance: IARC Press; 2004.

8. Jafri W, Yakoob J, Abid S, Siddiqui S, Awan S, Nizami SQ. Helicobacter pylori infection in children: population-based age-specific prevalence and risk factors in a developing country. Acta Paediatr 2010; 9: 279-82.a

9. Miwa H, Go MF, Sato N. Helicobacter pylori and gastric cancer: the Asian enigma. Am J Gastroenterol 2002; 97: 1106-12. [CrossRef]

10. Stolte M, Bayerdörffer E, Morgner A, et al. Helicobacter and gastric MALT Iymphoma. Gut 2002; 50: 11119-24. [CrossRef]

11. Everhart JE. Recent developments in the epidemiology of Helicobacter pylori. Gastroenterol Clin North Am 2000; 29: 559-78. [CrossRef]

12. Mazumder DN, Ghoshal UC. Epidemiology of Helicobacter pylori in India. Indian J Gastroenterol 1997; 16: S3-5.

13. Sarker SA, Rahman MM, Mahalanabis D, et al. Prevalence of Helicobacter pylori infection in infants and family contacts in a poor Bangladesh community. Dig Dis Sci 1995; 40: 2669-72. [CrossRef]

14. Edge SB, Byrd DR, Compton CC, et al. AJCC cancer staging manual. 7thed. New York: Springer, 2010. 
15. Hwang SW, Lee DH, Lee SH, et al. Preoperative staging of gastric cancer by endoscopic ultrasonography and multi-detector-row computed tomography. J Gastroenterol Hepatol 2010; 25: 51218. [CrossRef]

16. Karimi P, Islami F, Anandasabapathy S, Freedman ND, Kamangar F. Gastric cancer: descriptive epidemiology, risk factors, screening, and prevention. Cancer Epidemiol Biomarkers Prev 2014; 23: 70013. [CrossRef]

17. Yakoob J, Abbas Z. Agreement between serology and histology for detection of Helicobacter pylori infection. J Coll Physicians Surg Pak 2014; 24: 779-80.

18. Availablefrom:https://www.google.com.pk/webhp?sourceid=chromeinstant\&ion=1\&espv=2\&ie=UTF-8\#q=smoking\%20in\%20pakistan (accessed 29-July2016)

19. Iqbal SP, Dodani S, Qureshi R. Risk factors and behaviors for coronary artery disease (CAD) among ambulatory Pakistanis. J Pak Med Assoc 2004; 54: 261-6.

20. Rizvi SF, Khan MA, Kundi A, Marsh DR, Samad A, Pasha O. Status of rheumatic heart disease in rural Pakistan. Heart 2004; 90: 394-9. [CrossRef]
21. Jafar TH. Blood pressure, diabetes and increased dietary salt associated with stroke-results from a community-based study in Pakistan. J Hum Hypertens 2006; 20: 83-5. [CrossRef]

22. Jafar TH, Levey AS, White FM, et al. Ethnic differences and determinants of diabetes and central obesity among South Asians of Pakistan. Diabet Med 2004; 21: 716-23. [CrossRef]

23. Available from: http://diabetespakistan.com/treatment/2013/05/08/ diabetes-statistics-in-pakistan. accessed (31 July, 2016).

24. Lauren P. The two histological main types of gastric carcinoma: diffuse and so called intestinal-type carcinoma: an attempt at a histoclinical classification. Acta Pathol Microbiol Scand 1965; 64: 31-49.

25. Kaneko S, Yoshimura T. Time trend analysis of gastric cancer incidence in Japan by histological types, 1975-1989. Br J Cancer 2001; 84: 400-5. [CrossRef]

26. Layke JC, Lopez PP. Gastric cancer: diagnosis and treatment options. Am Fam Physician 2004; 69: 1133-40.

27. Ahmad Z, Idrees R, Azad NS, Ahmed R, Ahsan A, Asghar N. Gastric carcinoma: typing, staging, lymph node and resection margin status on gastrectomy specimens. J Coll Physicians Surg Pak 2004; 17: 539-42. 